\title{
Estudo clínico-epidemiológico de 41 casos de pitiose equina ocorridos na região Norte Fluminense do estado do Rio de Janeiro, Brasil
}

\author{
Clinical and epidemiological study of 41 equine pythiosis cases occurred in \\ the Northern Region Fluminense of Rio de Janeiro State, Brazil
}

Inácio Silva Viana (D*, Francielli Pereira Gobbi (D), Marcos Aurélio Dias Meireles, Gabriela Bravim Lemos (D), Paula Alessandra Di Filippo (D)

Laboratório de Clínica e Cirurgia Animal, Universidade Estadual do Norte Fluminense (UENF), Campos dos Goytacazes, RJ, Brasil

\section{Resumo}

Foram revisados os dados de quarenta e um casos de pitiose atendidos no Hospital Veterinário da Universidade Estadual do Norte Fluminense, Campos dos Goytacazes, Rio de Janeiro, nos anos de 2012 a 2018. Os animais eram provenientes dos municípios de Campos dos Goytacazes (31/41; 75,6\%), São João da Barra (07/41; 17,0\%), São Francisco do Itabapoana $(02 / 41 ; 4,8 \%)$ e São Fidélis $(1 / 41 ; 2,4 \%)$. Vinte animais $(48,7 \%)$ não possuíam raça definida, onze $(26,8 \%)$ eram Mangalarga Marchador, oito (19,5\%) Quarto de Milha, um (2,4\%) Paint Horse e um Apalusa (2,4\%), sendo as fêmeas mais acometidas $(24 / 41 ; 58,5 \%)$. A maioria dos casos ocorreu durante ou após períodos chuvosos e se concentraram nos meses de janeiro e fevereiro. Dentre dos animais acometidos, trinta e sete sobreviveram e quatro foram submetidos à eutanásia. $O$ tempo médio entre a ocorrência da lesão e o atendimento hospitalar variou de quatro dias a oito meses. O longo período necessário para tratamento associado ao seu alto custo foi apontado pelos proprietários como o principal fator limitante $(26 / 41 ; 63,4 \%)$. Conclui-se que o sucesso no tratamento pode ser alcançado através de diferentes protocolos farmacológicos associados ou não à ressecção cirúrgica, no entanto, o diagnóstico precoce, o tempo de desenvolvimento da doença, a extensão e o local de acometimento influenciam no índice de recuperação dos animais.

Palavras-chave: Doença do pântano. Formigueiro. Pitium. Pseudofungo. Cavalo. 


\section{Abstract}

Forty-one cases of pythiosis treated at the Veterinary Hospital of the North Fluminense State University, Campos dos Goytacazes, Rio de Janeiro, from 2012 to 2018, were reviewed. The animals were from the municipalities of Campos dos Goytacazes (31 / 41; 75.6\%), São João da Barra (07/41; 17.0\%), São Francisco do Itabapoana (02/41; 4.8\%) and São Fidélis (1/41; 2.4\%). Twenty animals (48.7\%) had no defined breed, eleven (26.8\%) were Mangalarga Marchador, eight (19.5\%) Quarter Horse, one (2.4\%) Paint Horse and one Appaloosa (2, 4\%), being the most affected females (24/41; 58.5\%). Most cases occurred during or after rainy periods and concentrated in January and February. Among the affected animals, thirty-seven survived and four were euthanized. The average time between injury occurrence and hospital care ranged from four days to eight months. The long period required for treatment associated with its high cost was pointed out by the owners as the main limiting factor $(26 / 41 ; 63.4 \%)$. It is concluded that success in treatment can be achieved by different pharmacological protocols associated or not with surgical resection, however, early diagnosis, time of disease development and extent and place of involvement influence the recovery rate of animals.

Keywords: Swamp disease. Anthill. Pythium. Pseudofungi. Horse.

\section{Introdução}

A pitiose é uma afecção crônica, sazonal, cosmopolita, piogranulomatosa e de caráter proliferativo (Sallis et al., 2003). Pode acometer animais domésticos e silvestres, como também o ser humano (Mendonza et al., 1996). A afecção é causada pelo Pythium insidiosum, microrganismo presente em substratos orgânicos de ambientes aquáticos, principalmente em regiões de clima subtropical, tropical ou temperado (Leal et al., 2001).

No Brasil, a maior ocorrência de pitiose é em áreas alagadas do Pantanal, onde a afecção recebe o nome de "doença brava" ou "doença da moda" (Santos et al., 2014). No Rio de Janeiro é conhecida como "formigueiro", sendo uma das enfermidades mais prevalentes do tecido cutâneo dos equinos da Baixada Campista, assim como em todo o Norte Fluminense. A pitiose gera prejuízos econômicos significativos para o agronegócio da equideocultura, uma vez que não há fármaco antifúngico eficiente contra o P. insidiosum (Santos et al., 2011). A doença pode acarretar morte, invalidez e/ou encerramento precoce da vida atlética dos animais acometidos (Álvarez et al., 2013).

Os métodos de diagnóstico preconizados incluem o exame histopatológico e o ensaio de imunoabsorção enzimática (ELISA). O tratamento consiste na remoção cirúrgica com ampla margem de segurança e administração de fármacos como a anfotericina $\mathrm{B}$, compostos de iodo, e imunoterapia (Dória et al., 2012). O sucesso, entretanto, depende da extensão da lesão, tempo de evolução, local acometido, idade e estado nutricional do animal (Dória et al., 2014). Relatos frequentes de insucesso ou recidivas são descritos (Mendonza et al., 1997).

Poucos estudos fornecem dados clínicoepidemiológicos da doença; assim, pesquisas que abordem protocolos terapêuticos, fatores de risco, métodos de controle, evolução e desfecho dos casos são relevantes. Diante disso, este trabalho teve por objetivo descrever e discutir dados clínico-epidemiológicos de 41 casos de pitiose equina diagnosticados na região Norte Fluminense do estado do Rio de Janeiro, no período de 2012 a 2018.

\section{Material e métodos}

Este estudo se refere a um levantamento dos casos de pitiose em equinos atendidos no Hospital Veterinário da Universidade Estadual do Norte Fluminense Darcy Ribeiro, HV/UENF, Rio de Janeiro, entre os anos de 2012 e 2018. Os dados foram obtidos a partir do acompanhamento da rotina diária, relatos, análises de dados clínicocirúrgicos e exames histopatológicos contidos em fichas arquivadas.

O diagnóstico de todos os casos foi baseado na anamnese, sinais clínicos, aspecto das lesões e avaliações histopatológicas. Para os exames de histopatologia, fragmentos representativos das lesões foram colhidos e fixados em formalina neutra 
a $10 \%$, posteriormente clivados, processados, incluídos em blocos de parafina, cortados à espessura de $5 \mu \mathrm{m}$ e submetidos às colorações de Hematoxilina e Eosina (HE) e Grocott.

Após o diagnóstico histopatológico os animais foram submetidos a diferentes tratamentos, baseando-se na localização e no tamanho daslesões, tempo de ocorrência e disponibilidade financeira do proprietário. Dessa forma, os protocolos terapêuticos constaram de exérese cirúrgica com ou sem posterior termocauterização a quente, terapia à base de iodeto de potássio $\left(67 \mathrm{mg} \mathrm{kg}^{-1}\right.$, SID, por 30 dias) e imunoterapia (três aplicações de Pithium Vac ${ }^{\circledR}$ via subcutânea, sendo uma a cada 14 dias até a remissão das lesões). Alguns animais foram submetidos concomitantemente a mais de um protocolo de tratamento.

\section{Resultados}

No período de 2012 a 2018, 41 equinos foram diagnosticados com pitiose. Os animais eram provenientes dos municípios de Campos dos Goytacazes (31/41; 75,6\%), São João da Barra (07/41; 20,0\%), São Francisco do Itabapoana $(02 / 41 ; 5,7 \%)$ e São Fidélis $(1 / 41 ; 2,8 \%)$, todas as cidades pertencentes à região Norte Fluminense do estado do Rio de Janeiro (latitude: - 21.7545, longitude: - 41.3244 e altitude: $11 \mathrm{~m})$. Dos 41 animais acometidos, 26 eram fêmeas $(63,4 \%)$ e 15 eram machos, sendo 10 castrados $(24,3 \%)$ e cinco garanhões $(12,1 \%)$. Os animais possuíam idade entre 5 meses e 15 anos. Vinte animais (48,7\%) não possuíam raça definida, onze $(26,8 \%)$ eram Mangalarga Marchador, oito (19,5\%) Quarto de Milha, um (2,4\%) Paint Horse e um Apalusa (2,4\%) (Tabela 1).

Treze casos foram registrados no ano de 2012 (31,7\%), sete em 2013 (17,0\%), dez em 2014 (24,3\%), dois em 2016 (4,8\%), três em 2017 $(7,3 \%)$ e seis em 2018 (14,6\%). Nenhum caso foi registrado no ano de 2015. A maioria dos casos se concentrou em janeiro e fevereiro, seguidos dos meses de março, abril e maio (Figura 1), durante ou após períodos chuvosos e de alta temperatura (Figura 2), sendo observada temperatura máxima de $39,2^{\circ} \mathrm{C}$ e mínima de $14,5^{\circ} \mathrm{C}$.

Os animais acometidos eram criados soltos a pasto, com histórico de alagamento nos períodos chuvosos (94,2\%), entretanto, alguns cavalos $(5,7 \%)$ eram criados exclusivamente em baias. $O$ tempo médio entre o desenvolvimento da lesão e o atendimento hospitalar variou de quatro dias a oito meses. Dos 41 casos, quatro $(9,7 \%)$ haviam recebido tratamento à base de anfotericina $B$ e imunoterapia e revulsivos anterior ao encaminhamento hospitalar, porém sem sucesso.

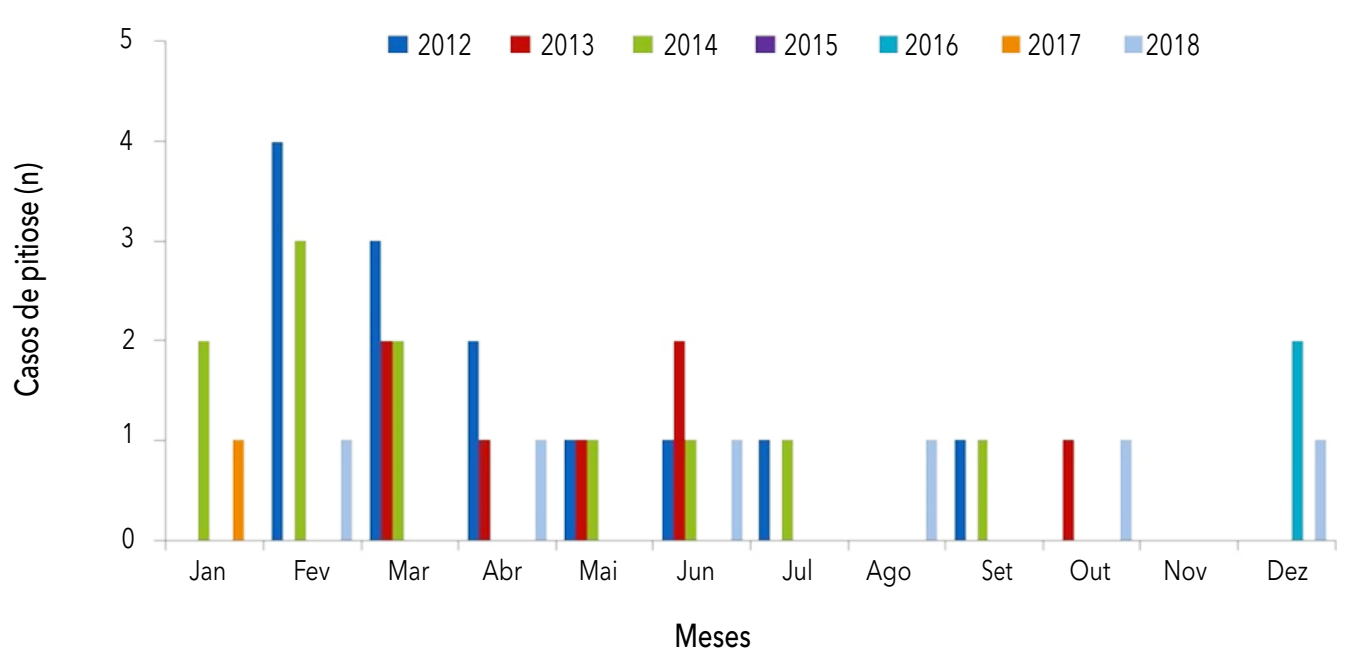

Figura 1 - Número de casos de pitiose equina diagnosticados no Hospital Veterinário da UENF, nos diferentes meses dos anos de 2012 a 2018. 


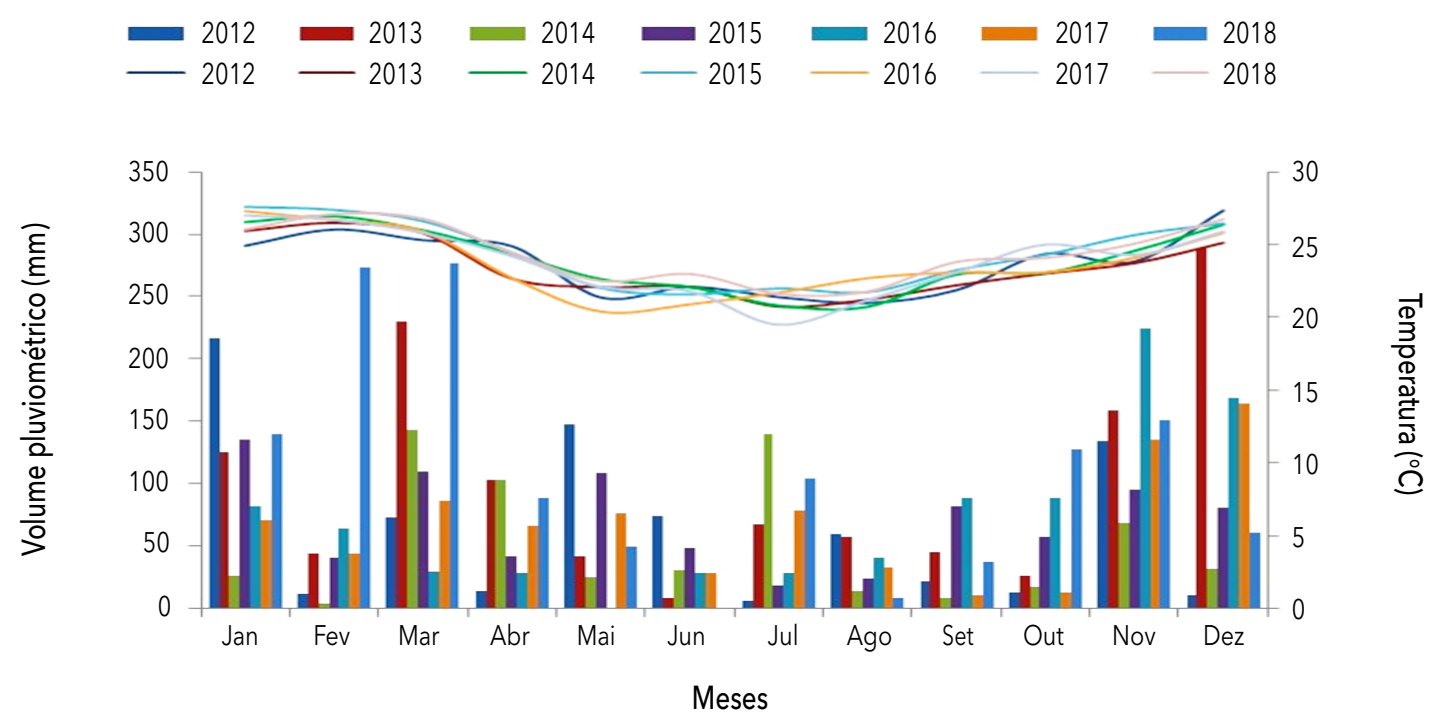

Figura 2 - Média mensal de volume pluviométrico (gráfico de barras) e temperatura (gráfico de linhas) referentes aos anos de 2012 a 2018. Fonte: Laboratório de Engenharia Agrícola-LEAG da UENF 2019.

Quanto à localização corporal das lesões, $29(70,7 \%)$ animais apresentavam feridas nos membros locomotores, seis $(14,6 \%)$ no tórax, abdômen ou úbere e seis $(14,6 \%)$ apresentavam lesões distribuídas em mais de uma região corpórea. Dos 41 cavalos, nove (21,9\%) apresentavam mais de uma lesão.

O tamanho da ferida variou de acordo com o local e o tempo de evolução. A maior lesão observada na abordagem inicial apresentou 42 $\mathrm{cm}$. Outros cinco animais possuíam lesões entre 25 e $30 \mathrm{~cm}(12,1 \%)$, sete entre 20 e $24 \mathrm{~cm}(17,0 \%)$, nove entre 15 e $19 \mathrm{~cm}(21,9 \%)$, nove entre $10 \mathrm{e}$

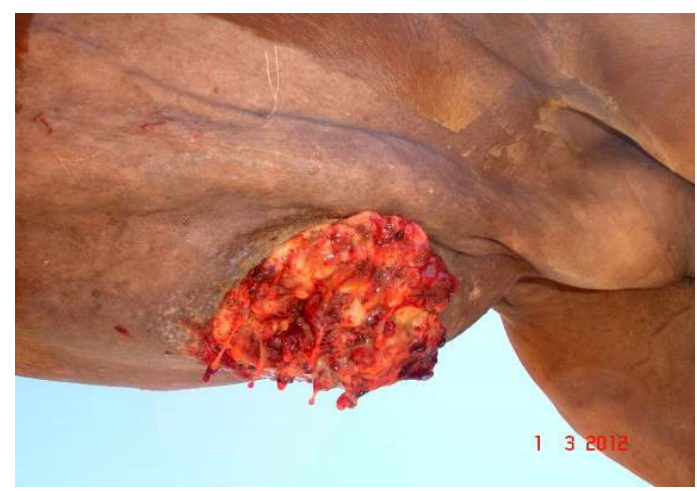

Figura 3 - Lesão abdominal sobressalente com secreção serossanguinolenta em equino.
$14 \mathrm{~cm}(21,9 \%)$ e onze entre 4 e $9 \mathrm{~cm}(26,8 \%)$. Dentre os $25,7 \%$ dos animais que apresentavam mais de uma lesão, estas possuíam tamanho entre 0,5 e $8 \mathrm{~cm}$.

As lesões possuíam bordos irregulares sobressalentes ou côncavas com aspecto ulcerativo e/ou granulomatosas, secreção serossanguinolenta ou mucossanguinolenta, odor fétido e prurido (Figuras 3 e 4), trajetos fistulosos formados pelo oomiceto em seu processo invasivo no tecido granular com áreas necróticas denominadas kunkers (95\%) com coloração branco amarelada.

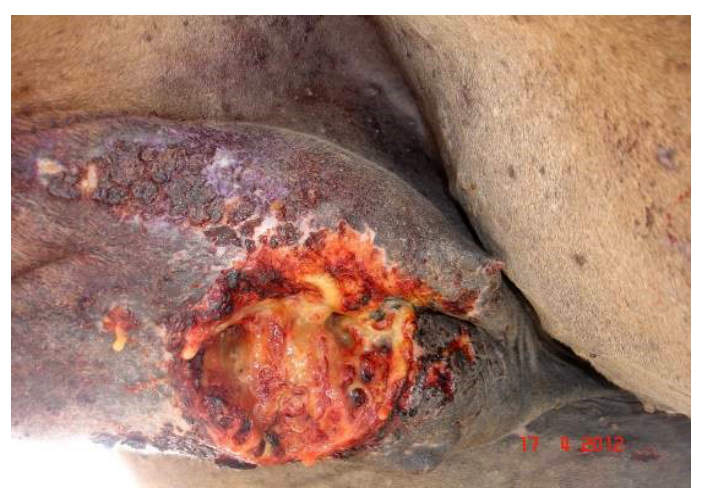

Figura 4 - Lesão côncava na glândula mamaria, com evidentes trajetos fistulosos formados pelo omiceto em equino. 
As características histopatológicas apresentaram ao redor de áreas necróticas infiltrados de eosinófilos, neutrófilos e células mononucleares. Proliferação de tecido conjuntivo fibroso e neovascularização também foram observadas. Estruturas denominadas de hifas foram identificadas no interior dos focos necróticos e hifas enegrecidas pela prata (Figura 5 e 6).

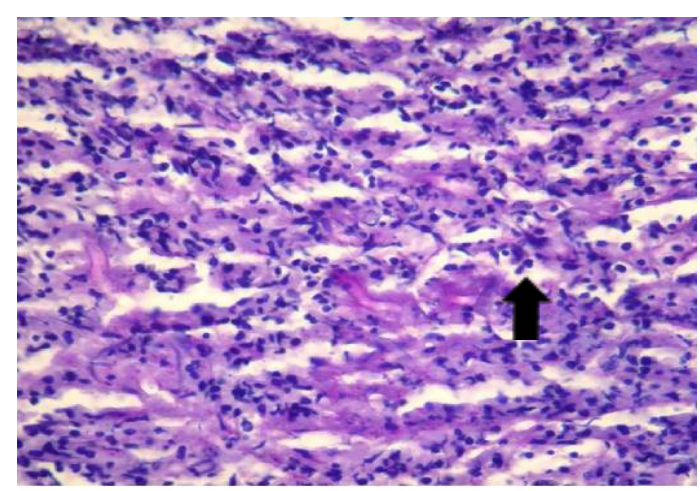

Figura 5 - Seta mostra hifa envolta por macrófagos eptelióides caracterizando o granulo micótico (coloração PAS 40X).

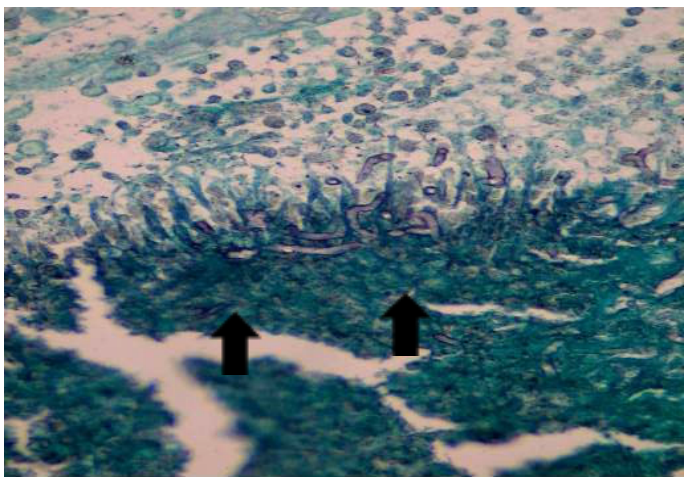

Figura 6 - Setas apontam presença de hifas de $P$. insidiosum na periferia de área de necrose (coloração Grocott 40X).

Do total de animais tratados, onze (11/41; $26,8 \%)$ foram submetidos à exérese cirúrgica da ferida como única modalidade terapêutica, obtendo sucesso em nove casos, três recidivaram e dois animais foram submetidos à eutanásia. Em cinco casos $(5 / 41 ; 12,1 \%)$, além da exérese cirúrgica, procedeu-se posterior termocauterização com ferro incandescente, não sendo observada recidiva ou necessidade de eutanásia em nenhum destes casos (Tabela 1).

Em outros onze casos (11/41, 26,8\%) foram implementadas terapias médicas concomitantes ao tratamento cirúrgico. Cinco animais (05/11) foram submetidos à remoção cirúrgica, cauterização à quente e, após ato operatório, receberam iodeto de potássio e imunoterápico. Destes, quatro se recuperaram, um apresentou recidiva e um foi submetido à eutanásia. Em seis casos (06/11) fez-se uso do mesmo protocolo de tratamento supramencionado, exceto pela termocauterização. Nestes foram obtidas três curas, duas recidivas e um animal foi submetido à eutanásia. Em um único animal (1/11) procedeuse a remoção cirúrgica, cauterização térmica e imunoterapia; em outro (1/11) caso, realizou-se ressecção cirúrgica e imunoterapia, não sendo observada recidiva ou necessidade de eutanásia em nenhum dos dois casos (Tabela 1). Nos animais em que a remoção cirúrgica da ferida foi realizada, o período de cicatrização variou de 15 a 90 dias, dependendo da extensão da lesão. Seis animais $(12 / 41 ; 29,2 \%)$ receberam apenas o iodeto de potássio como forma de tratamento e ambos apresentaram cura das lesões.

O índice de cura dos animais tratados, independente do tipo ou associação terapêutica utilizados, foi de 90,2\% (37/41). Quatro cavalos $(9,7 \%)$ foram submetidos à eutanásia mediante evolução desfavorável do processo de cura e avançado grau de comprometimento corporal. Dos quatro animais submetidos à eutanásia, dois $(4,8 \%)$ foram submetidos unicamente à exérese cirúrgica. Os outros dois animais (4,8\%) foram tratados com iodeto de potássio e imunoterapia.

Dentre os animais submetidos à eutanásia, dois apresentavam comprometimento dos ossos e tendões flexores, e os proprietários optaram pela eutanásia; um desenvolveu osteomielite metacarpiana e durante o tratamento apresentou fratura óssea espontânea, sendo então submetido à eutanásia (Figuras 7, 8 e 9). Um dos animais possuía uma grande lesão aderida ao peritônio, sendo que, após exérese cirúrgica, a massa removida pesou $8,6 \mathrm{~kg}$ (Figura 10). O animal em questão apresentava lesões há oito meses. 
Tabela 1- Distribuição de casos de pitiose cutânea atendidos na HV/UENF no período de 2012 a 2018

\begin{tabular}{|c|c|c|c|c|c|c|c|c|}
\hline \multirow[b]{2}{*}{$\mathrm{N}^{\circ}$} & \multicolumn{3}{|c|}{ Perfil do animal } & \multicolumn{3}{|c|}{ Perfil da lesão } & \multicolumn{2}{|c|}{ Perfil terapêutico } \\
\hline & Sexo & $\begin{array}{l}\text { Idade } \\
\text { (anos) }\end{array}$ & Raça & $\begin{array}{c}\text { Local } \\
\text { da lesão }\end{array}$ & $\begin{array}{l}\mathrm{N}^{\circ} \text { de } \\
\text { lesões }\end{array}$ & $\begin{array}{l}\text { Tempo de } \\
\text { evolução }\end{array}$ & Tratamento & Desfecho \\
\hline 01 & $M$ & 3 & SRD & MPE & 1 & $\mathrm{~N}$ & $\mathrm{RC}$ & Eutanásia \\
\hline 02 & $M$ & 14 & SRD & MPD & 3 & 20 dias & $\mathrm{RC}$ & Eutanásia \\
\hline 03 & $\mathrm{~F}$ & 3 & $\mathrm{QM}$ & MPD & 1 & 4 dias & $\mathrm{RC}, \mathrm{CA}$ & Cura \\
\hline 04 & $\mathrm{~F}$ & 1 & $\mathrm{QM}$ & Abdômen & 1 & 1 mês & $\mathrm{RC}$ & Cura \\
\hline 05 & $\mathrm{~F}$ & 5 & $\mathrm{QM}$ & MTD & 1 & $\mathrm{~N}$ & $\mathrm{RC}, \mathrm{CA}$ & Cura \\
\hline 06 & $\mathrm{~F}$ & 6 & SRD & MPD e úbere & 2 & $\mathrm{~N}$ & $\mathrm{RC}$ & Cura \\
\hline 07 & $\mathrm{~F}$ & 8 & SRD & MTD & 1 & 16 dias & $\mathrm{RC}, \mathrm{CA}$ & Cura \\
\hline 08 & $\mathrm{~F}$ & 1,5 & SRD & MTE e abdômen & 2 & 2 meses & $\mathrm{RC}$ & Cura \\
\hline 09 & M & 13 & $\mathrm{MM}$ & MTD & 1 & $\mathrm{~N}$ & $\mathrm{RC}$ & Cura \\
\hline 10 & $\mathrm{~F}$ & 5 & QM & Úbere & 1 & $\mathrm{~N}$ & $\mathrm{RC}$ & Cura \\
\hline 11 & M & 15 & SRD & MTD & 1 & 1 mês & $\mathrm{RC}, \mathrm{IP}$ & Cura \\
\hline 12 & $\mathrm{~F}$ & 4 & $\mathrm{PH}$ & MTE & 1 & 4 meses & $\mathrm{RC}$ & Cura \\
\hline 13 & M & 13 & QM & MTD & 3 & 15 dias & $R C, I M, I P$ & Cura \\
\hline 14 & $\mathrm{~F}$ & 12 & $\mathrm{MM}$ & Dorso, abaixo dos olhos e MTE & 5 & 8 meses & $R C, I M, I P$ & Cura \\
\hline 15 & $\mathrm{~F}$ & 0,5 & $\mathrm{QM}$ & MPD & 1 & $\mathrm{~N}$ & $\mathrm{RC}$ & Cura \\
\hline 16 & G & 8 & $\mathrm{MM}$ & Peitoral & 1 & 7 dias & $R C, C A, I M$ & Cura \\
\hline 17 & $\mathrm{~F}$ & 1,5 & SRD & MTE & 1 & 1 mês & $R C, C A, I M, I P$ & Cura \\
\hline 18 & $\mathrm{~F}$ & 7 & $\mathrm{QM}$ & Abdômen & 1 & 7 dias & $\mathrm{RC}, \mathrm{IM}$ e IP & Cura \\
\hline 19 & M & 8 & SRD & Abdômen e abaixo dos olhos & 2 & 8 meses & $R C, I M$ e IP & Eutanásia \\
\hline 20 & G & 6 & MM & MTE & 3 & 2 meses & $R C, C A, I M, I P$ & Eutanásia \\
\hline 21 & $\mathrm{~F}$ & 9 & $\mathrm{MM}$ & Abdômen & 1 & 4 meses & IP & Cura \\
\hline 22 & $\mathrm{~F}$ & 8 & SRD & MTD & 1 & 3 meses & $R C, C A, I M, I P$ & Cura \\
\hline 23 & $\mathrm{~F}$ & 12 & $\mathrm{QM}$ & MTE & 1 & 1 mês & RC, CA, IM, IP & Cura \\
\hline 24 & $\mathrm{~F}$ & 7 & SRD & Abdômen & 1 & 21 dias & IP & Cura \\
\hline 25 & M & 6 & $\mathrm{MM}$ & MTE & 1 & 1 mês & $\mathrm{RC}, \mathrm{IM}$ & Cura \\
\hline 26 & $M$ & 1,7 & SRD & MTD & 1 & 7 dias & $\mathrm{RC}$ & Cura \\
\hline 27 & $\mathrm{~F}$ & 2 & $\mathrm{MM}$ & MPE & 1 & 20 dias & $\mathrm{RC}, \mathrm{CA}$ & Cura \\
\hline 28 & $\mathrm{~F}$ & 2,8 & SRD & MTD & 1 & 26 dias & $\mathrm{RC}, \mathrm{CA}$ & Cura \\
\hline 29 & $\mathrm{~F}$ & 5 & $\mathrm{MM}$ & Abdômen & 7 & 2 meses & $\mathrm{RC}$ & Cura \\
\hline 30 & G & 7 & SRD & MTD e face & 3 & 4 meses & IP & Cura \\
\hline 31 & $\mathrm{~F}$ & 1 & SRD & MTE & 2 & 14 dias & IP & Cura \\
\hline 32 & $\mathrm{~F}$ & 8 & SRD & MTE & 1 & 2 meses & IP & Cura \\
\hline 33 & $\mathrm{~F}$ & 1 & SRD & Abdômen & 1 & 1 mês & $\mathrm{RC}, \mathrm{IP}$ & Cura \\
\hline 34 & $\mathrm{~F}$ & 5 & SRD & MTD & 1 & 15 dias & IP & Cura \\
\hline 35 & M & 2,5 & $\mathrm{MM}$ & Face & 1 & 4 meses & $\mathrm{RC}, \mathrm{IP}$ & Cura \\
\hline 36 & $\mathrm{~F}$ & 3,4 & SRD & MPE & 3 & 5 meses & IP & Cura \\
\hline 37 & $\mathrm{~F}$ & 4 & SRD & MPE & 2 & 2 meses & IP & Cura \\
\hline 38 & G & 2,8 & $\mathrm{MM}$ & MTD & 1 & 40 dias & IP & Cura \\
\hline 39 & $\mathrm{~F}$ & 3 & SRD & MTD & 1 & 3 meses & IP & Cura \\
\hline 40 & M & 6 & SRD & MPE & 1 & 1 mês & IP & Cura \\
\hline 41 & G & 7 & $\mathrm{AP}$ & MTD & 1 & 12 dias & IP & Cura \\
\hline
\end{tabular}

Nota: $\mathrm{F}$ = fêmea; $\mathrm{M}$ = potros e machos castrados; $\mathrm{G}$ = garanhão. $\mathrm{SRD}=$ sem raça definida; $\mathrm{QM}=$ Quarto de Milha; $\mathrm{MM}=\mathrm{Mangalarga}$ Machador; $\mathrm{PH}=$ Paint Horse; $\mathrm{AP}=$ Apalusa. $\mathrm{MTD} / \mathrm{MTE}=$ membro torácico direito/esquerdo; $\mathrm{MPD} / \mathrm{MPE}=$ membro pélvico direito/esquerdo; $\mathrm{N}=$ não soube dizer. $\mathrm{RC}=$ ressecção cirúrgica; $\mathrm{CA}=$ cauterização; $\mathrm{IP}$ = iodeto de potássio; $I \mathrm{M}=$ imunoterapia. 


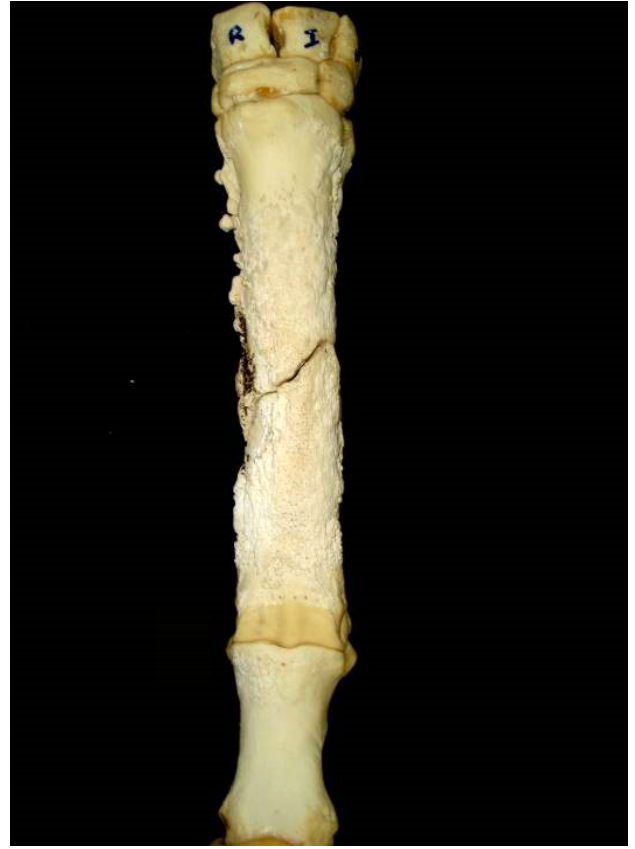

Figura 7 - Peça anatômica evidenciando a hiperostose devido à osteomielite provocada pela pitiose no $2^{\circ}$ e $3^{\circ}$ metacarpo e falange proximal em equino.

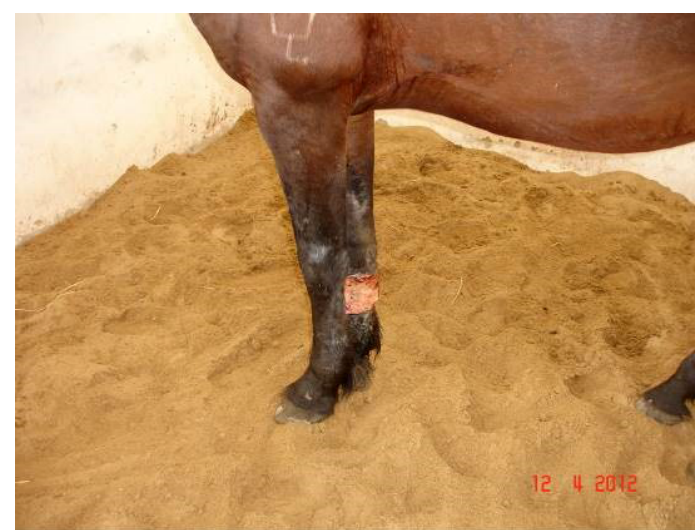

Figura 9 - Recidiva da lesão com presença de material endurecido, denominado kunkers, em equino.

\section{Discussão}

São muitas as enfermidades que afetam o tecido tegumentar dos equinos, no entanto, a pitiose se destaca frente ao grande acometimento (Souza et al., 2011). No período de abrangência deste estudo (2012 a 2018), 246 cavalos foram encaminhados ao HV/UENF

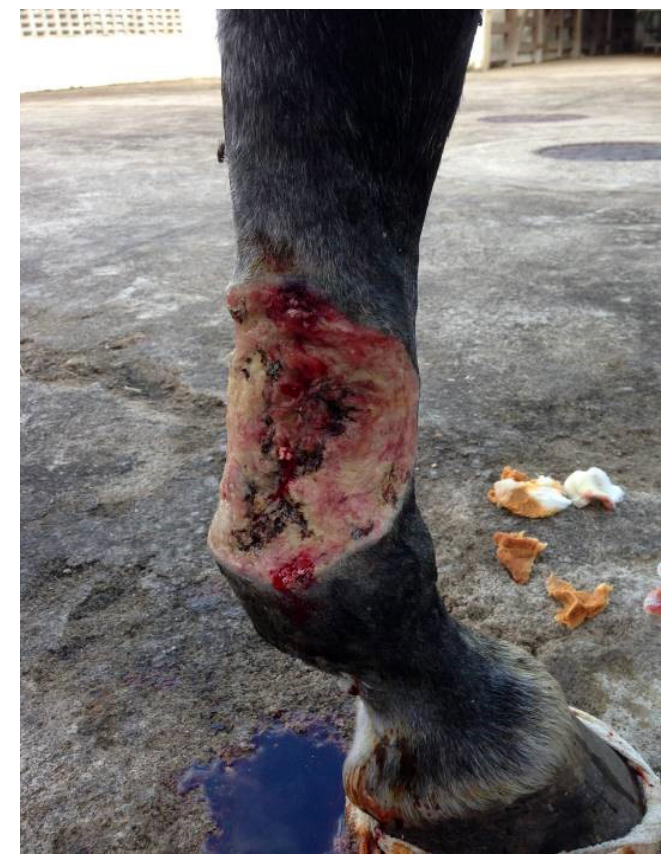

Figura 8 - Lesão após exérese com evidente comprometimento de tendões metacarpos em equino.

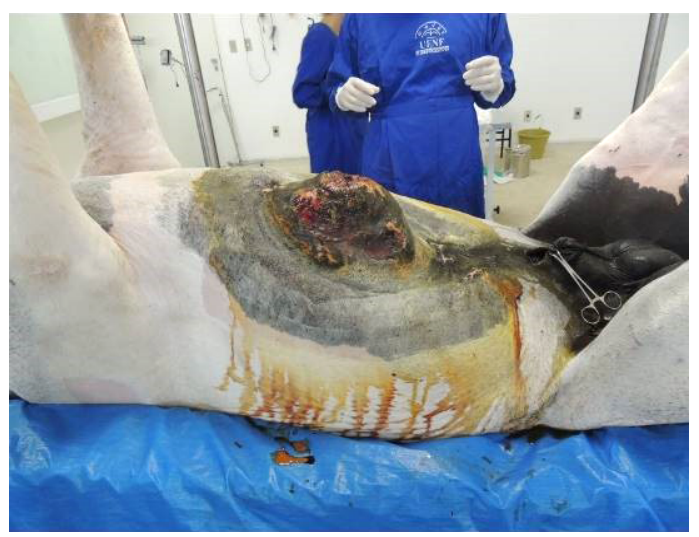

Figura 10 - Protuberante lesão abdominal aderida ao peritônio, com $45 \mathrm{~cm}$ de extensão e pesando $8,6 \mathrm{~kg}$, em equino.

apresentando afecções de pele. Deste total, 41 (41/246; 16,6\%) foram diagnosticados com pitiose. Similarmente, Pessoa et al. (2014), avaliando a casuística de doenças tegumentares em equinos na região de Patos/PB, identificaram que a pitiose foi a doença mais frequente. 
Frente os aspectos epidemiológicos, a pitiose chama atenção por ser a principal enfermidade infecciosa tegumentar em várias regiões do país, com média de 5,8 casos/ano registrados no presente estudo na região do Norte Fluminense, média superior às encontradas por MarcolongoPereiraet al. (2012) no Rio Grande do Sul (1,9 casos/ ano), Santos et al. (2011) na região de transição pantanal e cerrado (2,7 casos/ano), Watanabe et al. (2015) na região de Botucatu/SP (4,6 casos/ ano), e inferior às descritas por Santos et al. (2014) no Pantanal Mato-Grossense (16,2 casos/ano). No entanto ainda não há um levantamento preciso da incidência da pitiose no Brasil.

As condições ambientais são determinantes para o desenvolvimento do microrganismo em seu ecossistema (Marcolongo-Pereira et al., 2012). No período considerado neste estudo, a temperatura ambiental variou de $39,2{ }^{\circ} \mathrm{C}$ a $14,5{ }^{\circ} \mathrm{C}$ nos períodos de maior incidência da doença (Figura 2). Outro fator que também pode ter contribuído para a ocorrência da pitiose foi à topografia da região, a qual se torna constantemente alagadiça nos períodos de chuva. Tal característica ambiental já havia sido mencionada por Mendonça et al. (2012). A Baixada Campista, localizada no Norte Fluminense, às margens do trecho final do rio Paraíba do Sul, abrange os municípios de Campos dos Goytacazes, São João da Barra, São Francisco de Itabapoana e Quissamã. Essa região se caracteriza por uma vasta área de várzea originária de uma antiga baía que, após regressão marinha e ascensão continental, ocasionou uma planície de grande extensão; no entanto, a ocorrência de episódios extremos de precipitação tem gerado diversos problemas ambientais (Mendonça et al., 2012).

Ao avaliar a prevalência patológica mensal junto às médias pluviométricas e temperaturas mensais, tem-se que a maioria dos casos de pitiose ocorreram durante ou após a estação chuvosa (dezembro a março). Estes achados corroboram os de Santurio et al. (2006) e Santos et al. (2014), que demonstraram que para a produção de zoósporos são necessárias temperaturas entre 30 e $40^{\circ} \mathrm{C}$ e acúmulo de água em banhados e lagoas. A grande seca ocorrida no ano de 2015 pode justificar a ausência de casos da doença no referido ano.

$\mathrm{Na}$ Baixada Campista é comum observar equinos pastando dentro de lagos, várzeas e açudes. O tropismo do agente está diretamente relacionado com a parte do corpo do animal que está em contato com a água, atraindo os zoósporos. Consequentemente, neste estudo nota-se predomínio de lesões na porção distal dos membros $(70,7 \%)$ e na porção ventral do abdômen (14,6\%). Achados semelhantes também foram descritos por Leal et al. (2001), MarcolongoPereira et al. (2012) e Santos et al. (2014).

Na pitiose não há evidência de predisposição por sexo, idade ou raça, porém neste estudo, assim como em outros (Leal et al., 2001; Mosbah et al., 2012; Santos et al., 2014), as fêmeas foram as mais acometidas. Acredita-se que esse achado se deva ao fato de a região Norte Fluminense possuir grande número de centrais de reprodução e, nestas, as éguas utilizadas como receptoras de embrião serem maioria e predominantemente mantidas soltas no pasto no período da gestação, enquanto os garanhões, em menor número, são mantidos em baias.

Os aspectos macroscópicos das lesões se assemelham aos descritos na literatura, sendo caracterizados como ulcerações granulomatosas e granulocíticas sobressalentes, com bordas irregulares em forma de cratera, presença de secreção serossanguinolenta, odor similar à carne podre e presença de massas necróticas compostas de material endurecido, denominadas kunkers (Watanabe et al., 2015). Segundo Alvarez et al. (2013), na pitiose o processo da regeneração e cicatrização ocorre na presença de massas necróticas e calcificações que se desprendem facilmente e apresentam coloração branco-amarelada contendo hifas e infiltrado de eosinófilos, cujas dimensões variam de 2 a $10 \mathrm{~mm}$ de diâmetro, chamadas kunkers, juntamente à presença de prurido e secreção fibrinosanguinolenta (Biava et al., 2007; Alvarez et al., 2013).

Os sinais clínicos da pitiose são característicos, no entanto, o exame histopatológico deve ser realizado para a confirmação da suspeita clínica. À análise histopatológica das amostras deste 
estudo, observou-se proliferação de tecido de granulação com áreas de necrose, infiltrado de neutrófilos, macrófagos e granulomas eosinofílicos na derme superficial e profunda, compatível com relatos descritos por Leal et al. (2001) e Santos et al. (2014).

Quanto à confiabilidade do exame histopatológico para o diagnóstico da pitiose, estudo realizado por Dória et al. (2014) revelou que a análise histopatológica foi eficaz em 100\% dos casos avaliados, apresentando a mesma margem de segurança do exame de imuno-histoquímica. No entanto, tratando-se de lesões iniciais e de difícil diferenciação com outras lesões cutâneas, a imuno-histoquímica deve ser realizada (Santurio et al., 2006; Dória et al., 2014).

Existem diferentes formas de tratamento da pitiose e as escolhas se baseiam, geralmente, no custo do tratamento, na gravidade da doença, tempo de evolução da lesão e condição geral do animal (Dória et al., 2012). O tratamento cirúrgico apresenta bons resultados apenas quando realizado em lesões pequenas e superficiais, onde seja possível a retirada de toda a área afetada (Sallis et al., 2003). No presente estudo, 25 animais submetidos à exérese cirúrgica invasiva das lesões apresentaram recuperação satisfatória. No entanto quatro animais apresentavam invasão de estruturas importantes e inviáveis de serem totalmente removidas cirurgicamente. Estes animais foram submetidos à eutanásia durante o ato operatório.

Neste ensaio, a remoção cirúrgica seguida da termocauterização com ferro incandescente resultou na cura de nove animais. Destes, apenas um apresentou recidiva. Diferentemente dos resultados obtidos neste estudo, a remoção cirúrgica associada à termocauterização não foi satisfatória para a eliminação da pitiose no estudo descrito por Dória et al. (2012), no qual os animais tratados dessa forma apresentaram recorrência sete dias após o procedimento de remoção cirúrgica. Possivelmente, as lesões descritas por Dória et al., (2012) eram mais extensas, o que pode ter limitado a remoção da lesão com margem de segurança.

A terapia à base iodeto de potássio foi eficaz nos doze casos em que foi utilizada. Em outros onze animais $(26,8 \%)$ o fornecimento de iodeto de potássio foi associado à ressecção cirúrgica e à imunoterapia. Destes, sete animais apresentaram cura, registrou-se uma recidiva e dois foram sacrificados. Estudo realizado por Nascimento et al. (2010) revelou que todos os 25 cavalos com pitiose tratados com iodeto de potássio apresentaram cura total, não sendo necessária terapia adicional. Outros autores, contudo, relataram cura parcial e ocorrência de recidivas quando utilizado o iodeto de potássio como terapia única. Para os autores, terapias que atuem em sinergismo apresentam melhores resultados (Leal et al., 2001; Santurio et al., 2006).

No presente estudo, nove $(25,7 \%)$ animais foram tratados com imunoterapia e o sucesso foi alcançado em oito casos. Os resultados se assemelharam aos de Souza et al. (2011) e de Watanabe et al. (2015). As taxas de sucesso da imunoterapia no tratamento da pitiose são variáveis, podendo ser associada à ressecção cirúrgica e a outras manobras terapêuticas como a administração de anfotericina B e iodeto de potássio. Tais associações podem alcançar taxa de sucesso de 90\% (Mendonza et al., 1996; Santos et al., 2011).

Quatro cavalos $(9,7 \%)$ foram submetidos à eutanásia mediante evolução desfavorável do processo de cura. De acordo com Leal et al., (2001), Frey Jr et al. (2007) e Maciel et al. (2008), animais não tratados ou tratados tardiamente geralmente não respondem ao tratamento e culminam com o óbito ou com a necessidade de eutanásia. Tal desfecho se deve, possivelmente, à contaminação por bactérias gram negativas. Estes casos geralmente culminam com choque séptico e morte. A liberação de citocinas secretadas pelos fatores de necrose tumoral que induzem à lipólise promovem os fenômenos de caquexia, emagrecimento progressivo e morte (Leal et al., 2001).

\section{Conclusão}

A pitiose na região Norte Fluminense do estado do Rio de Janeiro é uma doença de caráter sazonal, com maior incidência no 
verão, após períodos chuvosos. A doença acomete equinos de todas as raças, idades e sexo, e o sucesso no tratamento pode ser alcançado a partir de diferentes protocolos. No entanto, o diagnóstico precoce, o tempo de desenvolvimento da doença, a extensão das lesões e o local de acometimento influenciam no índice de recuperação.

\section{Referências}

Biava JS, Ollhoff DR, Gonçalves RC, Biondo AW. Zigomicose em equinos - revisão. Rev Acad. 2007;5(3): 225-30.

Álvarez JC, José; Viloria MV, Ayola SP. Pitiose cutânea em equinos: uma revisão. Ces Med Vet Zoote. 2013;8(1):58-67.

Dória RG, Freitas SH, Linardi RL, Mendonça FS, Arruda LP, Boabaid FM, et al. Treatment of pythiosis in equine limbs using intravenous regional perfusion of amphotericin B. Vet Surg. 2012;41(6):759-65.

Dória RGS, Freitas SH, Mendonça FS, Arruda LP, Boabaid FM, Martins Filho A, et al. Utilização da técnica de imunohistoquímica para confirmar casos de pitiose cutânea equina diagnosticados por meio de caracterização clínica e avaliação histopatológica. Arq Bras Med Vet Zootec. 2014;66(1):27-33.

Frey Jr F, Velho JR, Lins LA, Nogueira CEW, Santurio JM. Pitiose equina na região sul do Brasil. Rev Port Cienc Vet. 2007;102(561-2):107-11.

Leal ABM, Leal AT, Santurio JM, Kommers GD, Catto JB. Pitiose equina no pantanal brasileiro: aspectos clínicopatológicos de casos típicos e atípicos. Pesq Vet Bras. $2001 ; 21(4): 151-6$.

Maciel ICF, Silveira JT, Maia CA, Sousa RM, Oliveira NJF, Duarte ER. Pitiose fatal em equinos tratado inicialmente para habronemose cutânea. Acta Sci Vet. 2008;36(3):293-7.

Marcolongo-Pereira C, Sallis ESV, Raffi MB, Pereira DIB, Hinnah FL, Coelho ACB, et al. Epidemiologia da pitiose equina na Região Sul do Rio Grande do Sul. Pesq Vet Bras. 2012;32(9):865-8.

Mendonça JC, Freitas RM, Shimabukuro YE, Marques VS. Avaliação de eventos de inundação na Região Norte Fluminense, Rio de Janeiro, utilizando imagens de sensores remotos. Rev Ambient Agua. 2012;7(1): 255-67.

Mendonza L, Ajello L, McGinnis MR. Infections caused by the oomycetus pathogen Pythium insidiosum. J Med Mycol. 1996;6:151-64.

Mendoza L, Kaufman L, Mandy W, Glass R. Serodiagnosis of human and animal pythiosis using na enzimelinked immunosorbent assay. Clin Diagn Lab Immunol. $1997 ; 4(6): 715-8$.

Mosbah E, Karrouf GIA, Younis EA, Saad HS, Ahdy A, Zaghloul AE. Diagnosis and surgical management of pythiosis in draft horses: report of 33 cases in Egypt. J Equine Vet Sci. 2012;32(3):164-9.

Nascimento RBS, Teixeira EF, Oliveira FCR. Hepatic and renal analysis in horses with pythiosis treated with potassium iodate, through the detection of serum proteins, nitrogenated substances and enzymes. Rev Bras Med Vet. 2010;32(2):105-10.

Pessoa AFA, Pessoa CRM, Miranda Neto EG, Dantas AFM, Riet-Correa F. Doenças de pele em equídeos no semiárido brasileiro. Pesq Vet Bras. 2014;34(8):743-8.

Sallis ESV, Pereira DIB, Raffi MB. Pitiose cutânea em eqüinos: 14 casos. Cienc Rural. 2003;33(5):899-903.

Santos CEP, Marques LC, Zanette RA, Jesus FPK, Santurio JM. Does immunotherapy protect equines from reinfection by the oomycete Pythium insidiosum? Clin Vaccine Immunol. 2011;18(8):1397-9.

Santos CEP, Ubiali DG, Pescador CA, Zanette RA, Santurio JM, Marques LC. Epidemiological survey of equine pythiosis in the Brazilian Pantanal and nearby areas: results of 76 cases. J Equine Vet Sci. 2014;34(2): 270-4.

Santurio JM, Alves SH, Pereira DB, Argenta JS. Pitiose: uma micose emergente. Acta Sci Vet. 2006;34(1):1-14. 
Souza TM, Brum JS, Fighera RA, Brass KE, Barros CSL. Prevalência dos tumores cutâneos de equinos diagnosticados no Laboratório de Patologia Veterinária da Universidade Federal de Santa Maria. Pesq Vet Bras. 2011;31(5):379-82.

Watanabe MJ, Alonso JM, Alves ALG, Yamada ALM, Bosco SMG, Rodrigues CA, et al. Equine pythiosis: report of 28 cases from São Paulo State, Brazil. Semina Cienc Agrar. 2015;36(2):909-16. 